(C) 1984. The Genetical Society of Great Britain

\title{
WILD BIRDS PREFER TO EAT THE MORE FAMILIAR OF ARTIFICIAL MORPHS THAT ARE SIMILAR IN COLOUR
}

\author{
JOHN A. ALLEN \\ Department of Biology, University of Southampton, Southampton SOg 3TU, England \\ Received 12.vi.84
}

\section{SUMMARY}

Colour polymorphisms in prey species can be maintained if predators preferentially hunt for common morphs. This hypothesis was tested in sixteen experiments by presenting "populations" of pastry prey to wild birds in their normal surroundings. The artificial morphs were more similar in appearance than those used in previous experiments. Groups of birds were trained on one colour and then presented with populations with the familiar and an unfamiliar colour in equal proportions. The birds were then trained on the second colour and again given an equal choice between the two. In eight of the experiments the birds were also presented with " $1: 1$ " populations before the first session of training. Overall, there was good evidence that the birds preferred the familiar colour after the first training, and this effect was less marked after the second training.

\section{INTRODUCTION}

Apostatic selection occurs when predators kill disproportionately more common prey to the advantage of rare prey. It is thus capable of maintaining non-mimetic colour polymorphisms within prey species (Clarke, 1962). Its strength is known to be affected by a number of variables, and these include prey density (Allen, 1972; Cook and Miller, 1977; Horsley, Lynch, Greenwood, Hardman and Mosely, 1979; Willis, McEwan, Greenwood and Elton, 1980; Allen and Anderson, 1984), palatability (Greenwood, Wood and Batchelor, 1981) and the degree of colour match of the morphs to the background (Bond, 1983; Cooper, 1984).

Most tests of apostatic selection have used a choice between artificial prey that were very different in colour (brown and green: Allen and Clarke, 1968, Allen, 1972, 1974, 1976, Horsley et al., 1979, Greenwood et al., 1981; yellow and green: Horsley, 1978; yellow and red: Oates (in Cook, 1971), Greenwood et al., 1981; blue and red: Manly, Miller and Cook, 1972, Cook and Miller, 1977, red, yellow and green: Willis et al., 1980; orange and grey: Cooper, 1984; pink and yellow: Harvey, Birley and Blackstock, 1975). The morphs in some natural non-mimetic polymorphisms are also very different in colour but were probably less so in their evolutionary past. Moreover, in many contemporary species the "dissociation" (Murray, 1972) of the morphs is slight. It follows that it is important to know whether predators behave in a manner that will lead to apostatic selection when the morphs are similarly coloured.

Allen and Clarke (1968), Allen (1974), Bantock and Harvey (1974), Harvey et al., (1975) and Raymond (1984) have all used the same basic design to test for behaviour that could lead to apostatic selection. Predators are exposed to populations of one type of prey. Wild birds thus "trained" on populations of either green or brown pastry prey preferred the more 
familiar of the two colours when offered in equal numbers (Allen and Clarke, 1968; Allen, 1974), and I now report on the occurrence of a similar "training bias" (Bryan, 1973; Curio, 1976) when the artificial morphs resemble one another more closely.

\section{MATERiAls AND METHODS}

\section{(i) Prey}

The prey were lard and flour cylindrical baits ( $7 \mathrm{~mm}$ long $\times 6 \mathrm{~mm}$ wide) made by a method similar to that described by Allen (1974). Brown pastry was made by adding $11 \mathrm{ml}$ of "Coffee Brown" (K6029) food colouring to every $1 \mathrm{~kg}$ of dough and green pastry was made by adding $11 \mathrm{ml}$ of "Pea Green" (K6026) food colouring to every $1 \mathrm{~kg}$ of dough (dyes supplied by Edinburgh Essence and Flavour Co. Ltd. and their successors, Pointing Ltd.). Baits made from these two "standard" colours matched the colours of those used in other experiments (e.g., Allen, 1974, 1976) and formed the two extremes of the colour range of the prey. Seven intermediate colours were made by mixing the two types of dough in the required proportion by weight. The nine morphs were numbered 0-8 in order of increasing greeness. For example, 0 was standard brown, 2 was made from two parts green pastry to six parts brown, 4 was made from equal parts green and brown pastry, and $\mathbf{8}$ was standard green. Reflectance surves of the seven colours used in the experiments are given in fig. 1 (colours 1 and 7 were not used).

\section{(ii) Predators}

The predators were wild passerine birds in their normal surroundings. The commonest species were the Blackbird Turdus merula L., Songthrush T. philomelos Brehm., House Sparrow Passer domesticus L., Dunnock Prunella modularis L., Robin Erithacus rubecula Hart., Chaffinch Fringilla coelebs L., Blue Tit Parus caeruleus L., Great Tit P.-major L., Magpie Pica pica L. and Starling Sturnus vulgaris L.

\section{(iii) Method}

Sixteen experiments were carried out between 1969 and 1982. The work was organised into four series, each consisting of four experiments (for sites and dates see tables 1 and 2). Series I was in Edinburgh, Scotland (Allen, 1973) and series II-IV were in and near Southampton, England.

All the experiments were on grass backgrounds. All involved two periods of training and two periods of presentation of "populations" with two colours of prey in equal numbers. During training, about 200 baits of one colour were scattered daily over the site for one week. The " $1: 1$ " populations were presented for two or three days and maintained as described by Allen (1974). The populations consisted of 50 baits (series I), or 100 baits (series II-IV), at a density of $2 \mathrm{~m}^{-2}$. The random spatial distribution of the baits was altered frequently and eaten baits were replaced as often as practicable in order to maintain the $1: 1$ ratio. The numbers eaten by blackbirds and songthrushes ("thrushes") were recorded from direct observation of the 

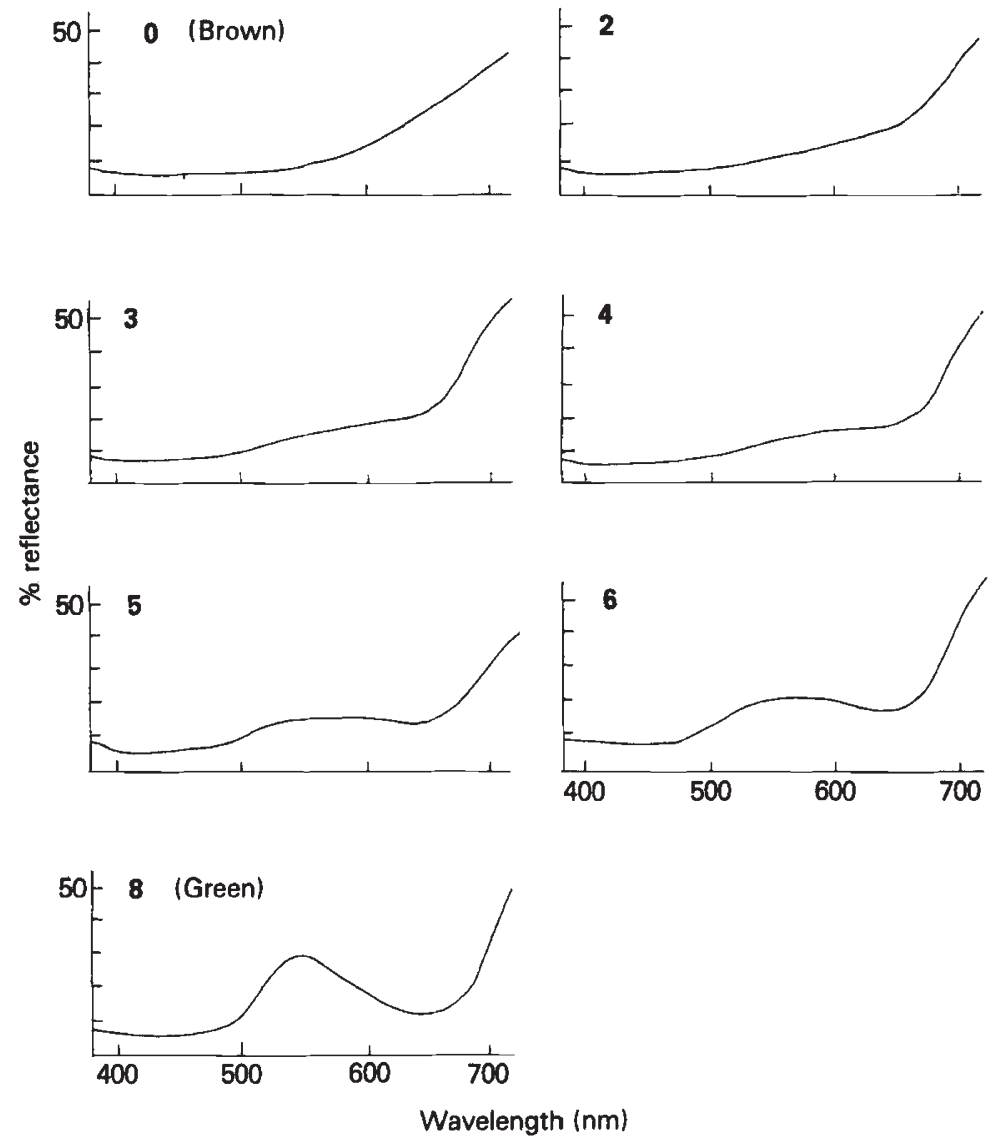

FIG. 1. Reflectance curves of the seven colours of pastry used in the experiments, estimated by reflectance spectrophotometry using the Pacific Scientific Spectrogard System. Note the high per cent reflectance towards the infra-red (wavelength $>$ c. $650 \mathrm{~nm}$ ). Like humans, birds (i.e., pigeons) are believed to be almost insensitive to such long-wave radiation (Wright, 1979).

birds. Predation by other species was recorded either from direct observation or, where thrushes were feeding, by counting the prey remaining and subtracting the numbers taken by thrushes.

In every experiment, 4 was one of the two colours. In series I and II the other colour of the pair was $\mathbf{0 , 8 , 2}$ or $\mathbf{6}$. In series I the birds were given $4 \mathrm{~s}$ in their first training sessions and the other colour in their second training sessions. In series II the training sessions were in the reverse order. Selection on the $1: 1$ populations was compared with an expectation based on random predation, and in each experiment a comparison was also made between the proportions eaten after the two training periods.

The experiments of series III and IV followed the design suggested by Bantock and Harvey (1974) in that an additional "pretraining" 1:1 population was presented immediately before the first training session. Selection on the $1: 1$ populations presented after training could therefore be compared with selection on the control 1:1 populations. The second colour of each 


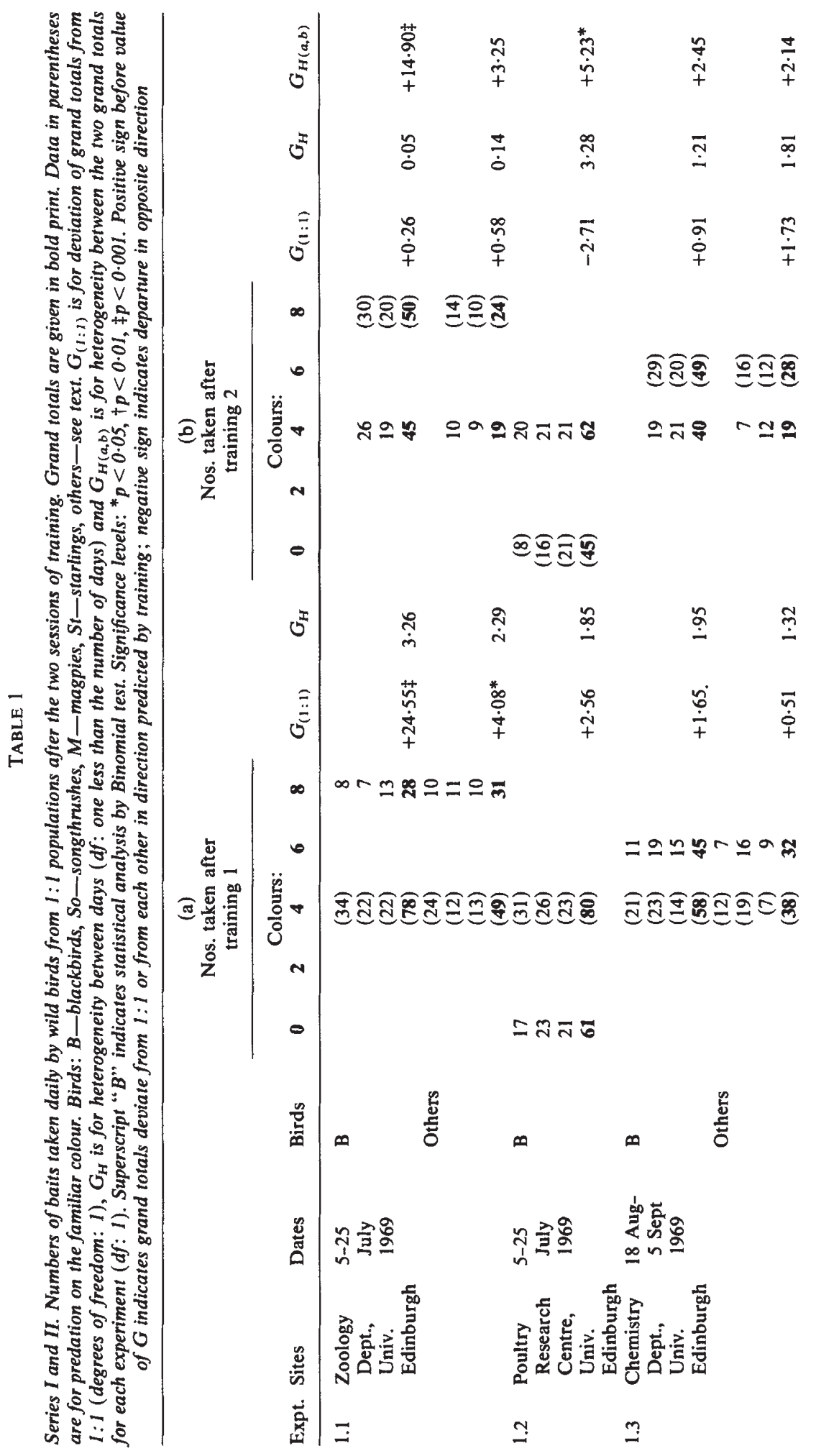




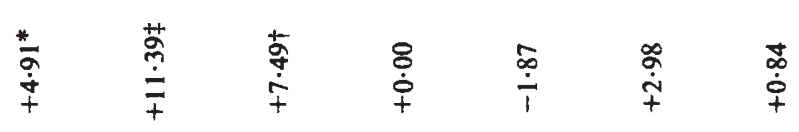

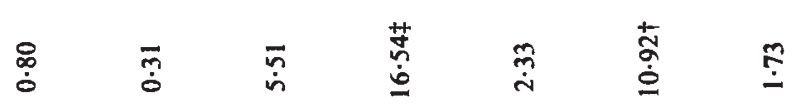

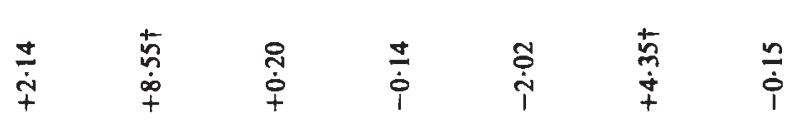
$\sim \operatorname{*n} \varrho \simeq \simeq=8$

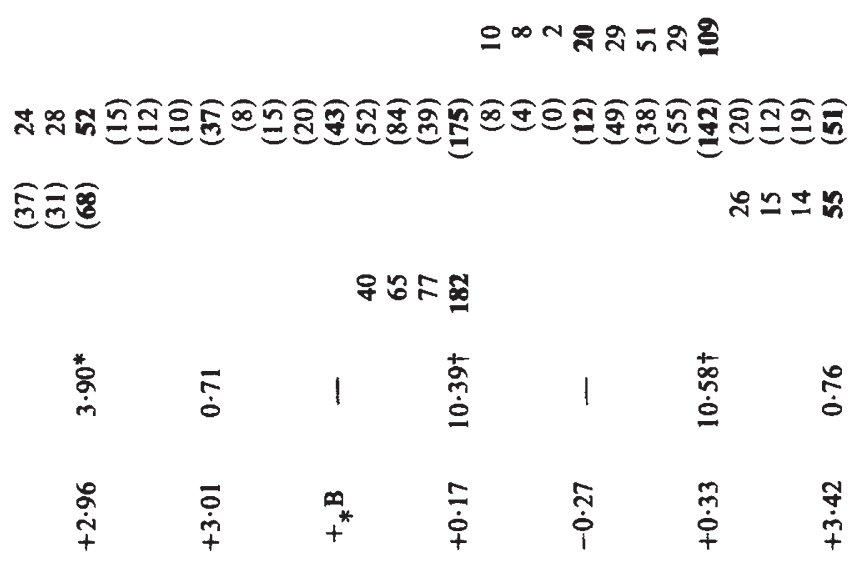

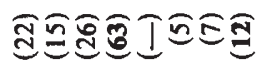

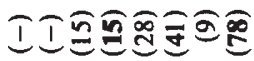

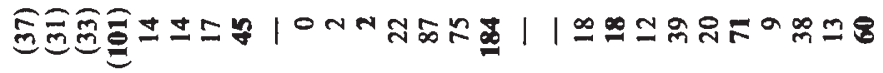
으윰유뭉

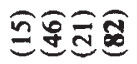

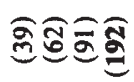

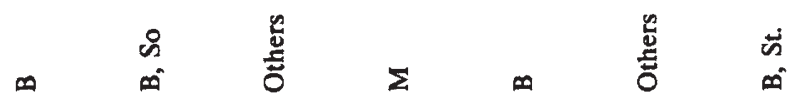

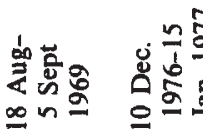

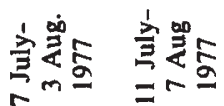

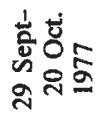

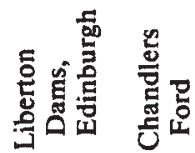

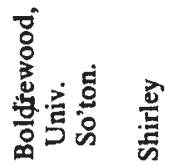

$\pm \quad \bar{i}$

ก $\quad$ ก

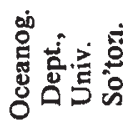

$\stackrel{+}{i}$ 
pair, 3 or 5 , was more similar to 4 than those used in series I and II. In two experiments in each series the birds were first trained on $4 \mathrm{~s}$ and then on $3 \mathrm{~s}$ or $5 \mathrm{~s}$, while in a third experiment they were trained on $3 \mathrm{~s}$ and then $4 \mathrm{~s}$, and in the fourth they were trained on $5 \mathrm{~s}$ and then $4 \mathrm{~s}$.

All statistical tests were two-tailed. Probability values of less than 0.05 were regarded as indicating statistical significance.

\section{Results}

\section{(i) Series $I$ and $I I$}

Table 1 gives the data resulting from series I and II. The numbers of the more familiar baits eaten are in parentheses and the grand totals for the two halves of each experiment are in bold print.

In four experiments data were obtained for thrushes and other birds separately, giving a total of twelve pairs of grand totals. Overall, nineteen of the twenty-four grand totals deviate from an expected $1: 1$ ratio in the direction predicted if the birds prefer the familiar colour, and this tendency is statistically significant $(p=0.006$, Sign test). In five grand totals the deviations from $1: 1$ were statistically significant (analysis by $G$-test, Sokal and Rohlf, 1981: columns in table 1 headed " $G_{1: 1}$ "). Direct comparison of the two grand totals for each experiment shows that five of the twelve pairs deviate significantly from one another in the direction predicted by training (columns headed " $G_{H(a, b)}$ "), and overall the effect is significant ( $T=12, N=12, p<0.05$, Wilcoxon matched-pairs test).

Analysis of the grand totals must be treated with caution, however, because of the five occasions when the heterogeneity between days was statistically significant (columns headed " $G_{H}$ " in table 1 ). This problem is avoided when predation on the first and second days is considered separately. (Data are too few for conclusions to be drawn from day 3 ). On day 1 , an excess of the familiar colour was eaten in nine of the twelve sets of data obtained after training 1 , and also in nine of the twelve sets obtained after training 2. The effect of training is also clear when we compare directly the proportions eaten in the two halves of the experiments. Baits of a given colour were taken at a higher frequency when familiar after training 1 compared with when they were unfamiliar after training $2(T=5, N=12$, $p<0.01$, Wilcoxon test). For day 2 , an excess of the familiar colour was taken ten times out of eleven after the first training, and six times out of twelve after the second training. Once again, baits were taken at a higher frequency when familiar $(T=11, N=11, p<0.05)$.

There is some evidence that the birds were more likely to eat familiar baits when the colour of these was most distinct from the colour of the unfamiliar baits. The grand totals can be grouped into those from experiments with dissimilar colours ( $4 s$ and $0 s$, and $4 s$ and $8 s$ ) and those from experiments with similar colours ( $4 \mathrm{~s}$ and $2 \mathrm{~s}$, and $4 \mathrm{~s}$ and $6 \mathrm{~s}$ ). For predation after training 1 , higher proportions of the familiar colours were eaten in the first group compared with the second but the tendency is not formally statistically significant (Mann-Whitney test: $U=6, n_{1}=n_{2}=6, p=0.06$ ). There is no significant difference in the proportions taken after training 2 $\left(U=18, n_{1}=n_{2}=6, p>0.9\right)$. 


\section{(ii) Series III and IV}

Table 2 gives the data from series III and IV. Subdivision of five of the experiments into predation by thrushes and other birds provides thirteen sets of data.

For each data set, the proportion of the two colours eaten from the pretraining $1: 1$ populations gives a measure of the selection by the birds in the absence of training. In two experiments (3.4 and 4.4) the departure of the grand totals from an expected $1: 1$ ratio is statistically significant. Although the pretraining grand totals of experiments 3.2 ("others") and 3.3 do not deviate significantly from a $1: 1$ ratio, conclusions from analysis based on these results must be regarded as tentative because of the appreciable heterogeneity between days (column headed " $G_{H}$ ").

We now examine the effects of training. A comparison between the grand totals for predation on $1: 1$ populations before and after training 1 shows that the familiar colour was taken in excess in twelve of the thirteen data sets $(p=0 \cdot 002$, Sign test $)$. In six cases the deviations are statistically significant (column headed " $G_{H(a, b)}$ "). A similar comparison between the grand totals for pretraining and training 2 reveals an increased risk to the familiar colour in only seven of the thirteen pairs (not significant, Sign test), and in only one of these seven was the deviation from the pre-training ratio statistically significant (column headed " $G_{H(a, c)}$ "). The implication that familiar colours were at greater risk after training 1 than training 2 is confirmed when we take into account the magnitude as well as the direction of the differences within pairs of grand totals. A comparison between the frequencies of colours taken during pretraining and the frequencies of the same colours when familiar after training 1 gives: $T=7 \cdot 5, N=13, p<0.01$, (Wilcoxon test). For a similar comparison between predation pre-training and after training 2: $T=42, N=13$, not significant. Direct comparison between the grand totals for predation after training 1 and training 2 (as was carried out for series I and II) confirms the finding above. Within twelve of the thirteen pairs the proportions deviate in the direction expected from the prediction that the birds take an excess of the familiar colour after one (or both) of the training sessions (column headed " $G_{H(b, c)}$ ").

Five of the grand totals of baits eaten after training hide statistically significant heterogeneity in the proportions taken between days (columns headed " $G_{H}$ "). In one case (experiment 3.4 ) the proportions eaten daily all deviate in the direction predicted by training and the heterogeneity reflects variation in the magnitude of the deviations. In experiments 3.2 , 3.3 and 4.1 (both training periods) the heterogeneity appears to result from an increased frequency of predation on the unfamiliar form after the first day. In other words, analysis based on the grand totals is valid, since these pooled data tend to provide an underestimate of the initial effects of training.

\section{Discussion}

The results agree with other findings that wild birds can be trained to feed on familiar prey (Allen and Clarke, 1968; Allen, 1974; Harvey et al., 1975; Raymond, 1984). They therefore lend more weight to the argument that apostatic selection could maintain colour polymorphisms. Chance encounters with common morphs could result in predators acquiring 


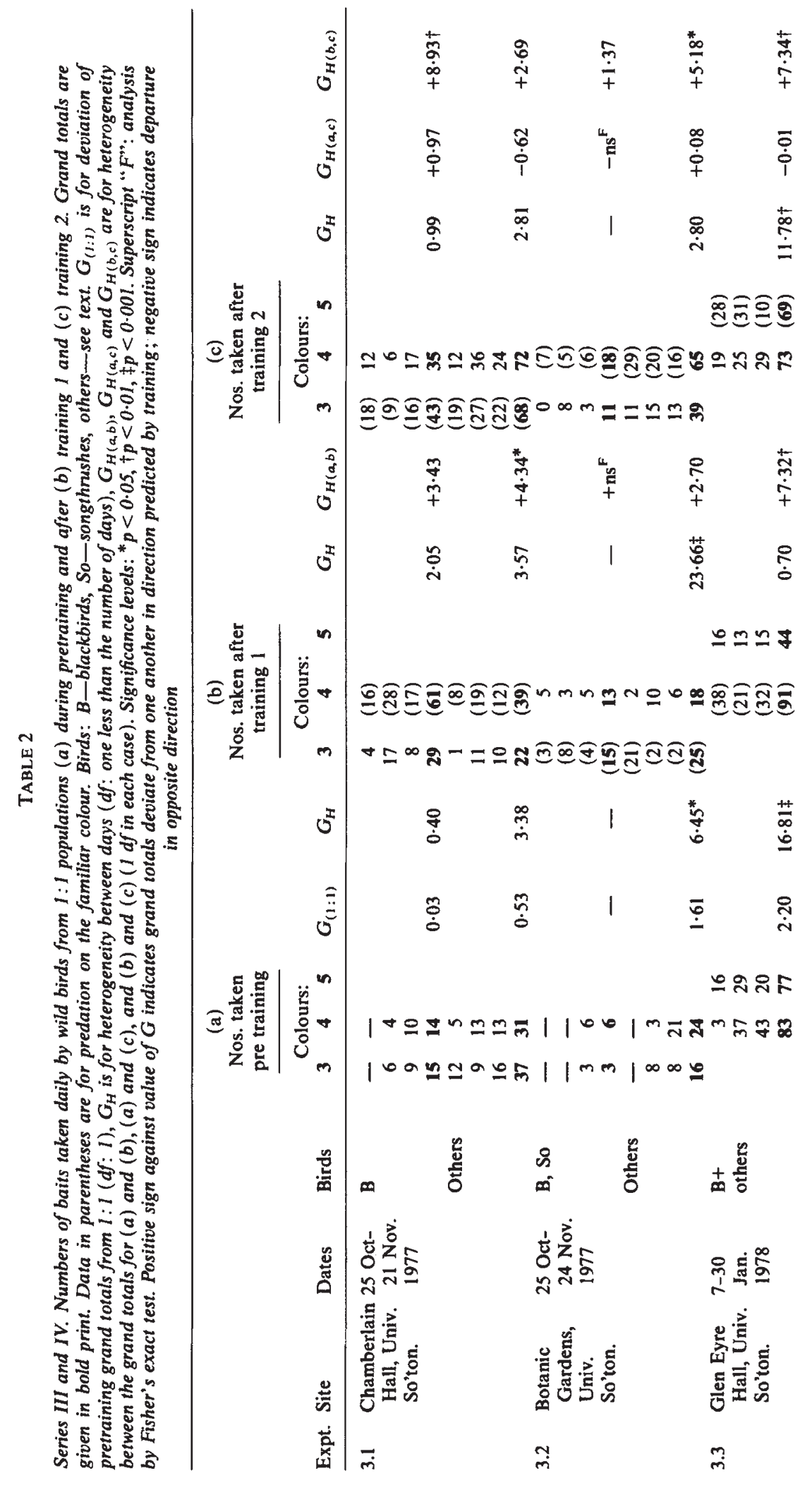




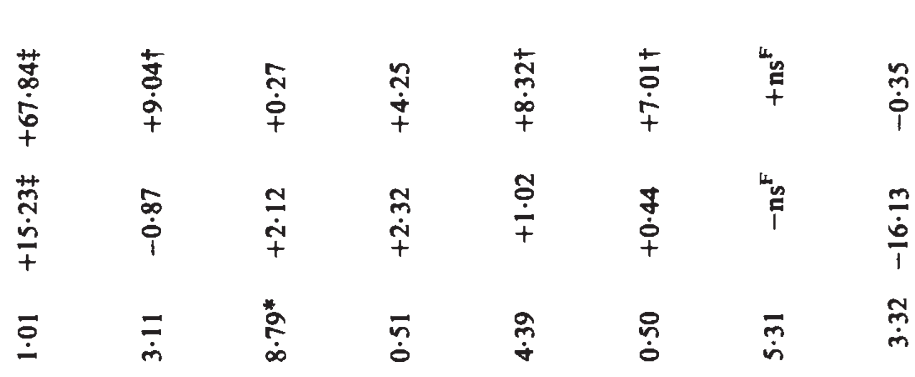

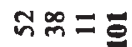

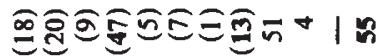

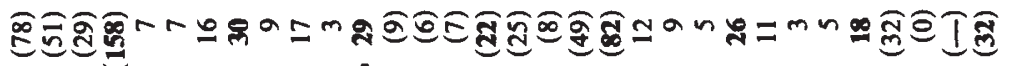

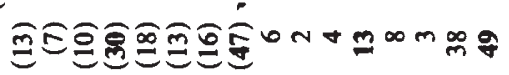

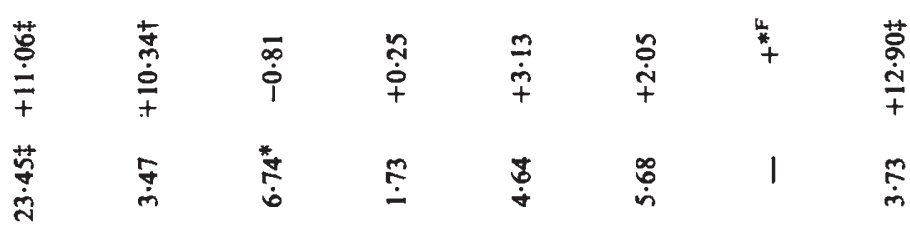

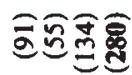

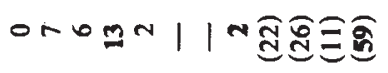

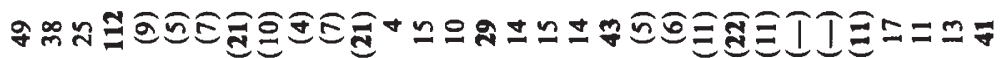

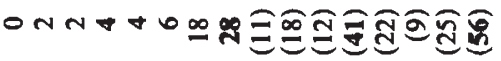

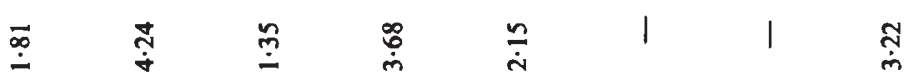

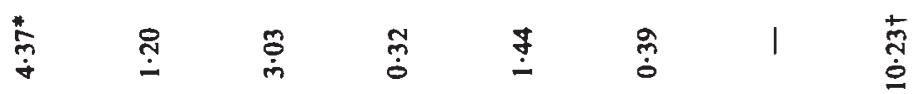

유ำำ

$|19 m-| 1 r+a+\theta$

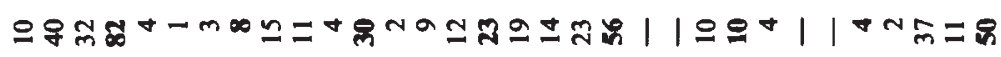

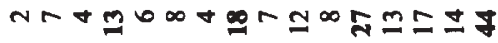

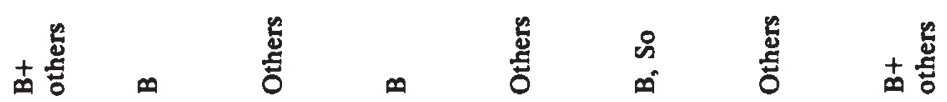

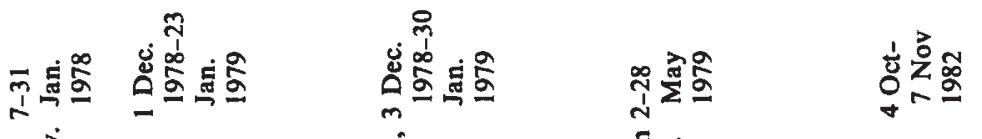

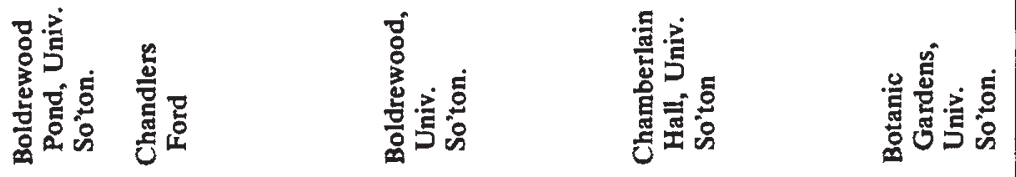

$\stackrel{+}{\dot{m}} \underset{+}{\ddot{*}}$

พ

$\stackrel{m}{*}$

$\stackrel{+}{+}$ 
preferences for these morphs, and such preferences could be stronger than those acquired for rare morphs. The fitness of a morph would then be inversely related to its frequency and the polymorphism would be maintained (Clarke, 1962; Moment, 1962).

The most important conclusion from the current work is that the wild birds developed preferences for familiar prey that were similar in colour to unfamiliar prey. In other words, the preferences were quite specific. Croze (1970) also found that two Carrion Crows (Corvus corone L.) used precise colour cues when they searched for the more familiar of similarly painted sea-shells covering pieces of meat. The shells were cryptic and it is safe to assume that the Crows learned to distinguish them from the background; that is, they hunted by "specific search images" (Tinbergen, 1960; Dawkins, 1971; Lawrence and Allen, 1983; Lawrence, 1985). The baits in my work were not deliberately made cryptic and therefore search images were not necessarily involved.

Whatever the behavioural mechanism(s) underlying the preferences, there is some evidence that the greater the colour difference between the unfamiliar and the familiar prey, the greater the chance that the unfamiliar prey was overlooked (as predicted from Clark, 1962 and Rand, 1967). Thus Allen (1974) carried out training experiments identical in design to those described in series $\mathbf{I} / \mathbf{I I}$, but using brown (0) and green (8) baits. After training, only the familiar colour was eaten in eleven out of fourteen sets of "data. The effects of training were thus more marked than in the series I/II experiments with $0 \mathrm{~s}$ and $4 \mathrm{~s}$ and $8 \mathrm{~s}$ and $4 \mathrm{~s}$. Furthermore, although the effect was not statistically significant, birds trained on $4 \mathrm{~s}$ in series $\mathrm{I} / \mathrm{II}$ took higher proportions of $2 \mathrm{~s}$ and $6 \mathrm{~s}$ than those of the more different $0 \mathrm{~s}$ and $8 \mathrm{~s}$ (after the first training sessions only). However, a comparison between the grand totals after the first training in series I/II and series III/IV provides an inexplicable finding. The familiar colours were taken at significantly higher frequencies in series III/IV $\left(U=10, n_{1}=6, n_{2}=13, p=0.02\right)$. This result was obtained in spite of the fact that (1) the colours were more similar than in series I/II, and (2) pretraining ensured that some birds encountered the "unfamiliar" colour before training. Intuitively, these two factors should have decreased the magnitude of the training bias.

The results also agree with those of Allen (1974) in that the effects of training decreased as the birds became more acquainted with the unfamiliar baits. This was reflected in the less pronounced selection of the familiar colour in the second training sessions of the experiments of both series I/II and III/IV.

In conclusion, the data support the idea that apostatic selection by predators could maintain colour polymorphisms in which the differences between the morphs are slight. Other recent work has shown that wild birds form preferences for familiar pastry prey that differ in their patterning (Raymond, 1984). Nevertheless, although Harvey et al., (1975) made a promising start with Cepaea shells stuffed with breadcrumbs, the following words still stand: "the most important point now is whether sight-dependent predators can be trained to search for a particular morph of a natural polymorphic species" (Allen, 1974, p. 370).

Acknowledgements. I thank Professor Bryan Clarke for his help in the early part of this work and for constructive criticism of the manuscript. I also thank Jon Cooper, Simon Lawrence, Debbi Raymond, Keith Anderson and a referee for their comments. Sue Coxson 
and Helen Kellar helped with the preparation of the manuscript. I am grateful to Mr D. I. Chamberlin of Tintometer Ltd. for obtaining the reflectance curves of the baits. The work was supported initially by a Research Studentship from the then Science Research Council and latterly by the University of Southampton.

\section{REFERENCES}

ALLEN, J. A. 1972. Evidence for stabilizing and apostatic selection by wild passerines. Nature, 237, 348-349.

ALLEN, J. A. 1973. Apostatic selection: the responses of wild passerines to artificial polymorphic prey, Ph.D. thesis, University of Edinburgh.

ALLEN, J. A. 1974. Further evidence for apostatic selection by wild passerine birds: training experiments. Heredity, 33, 361-372.

ALLEN, J. A. 1976. Further evidence for apostatic selection by wild passerine birds-9:1 experiments. Heredity, 36, 173-180.

ALLEN, J. A. AND ANDERSON, K. P. 1984. Selection by passerine birds is anti-apostatic at high prey density. Biol. J. Linn. Soc., 23 (in press).

AlleN, J. A. AND ClARKE, B. C. 1968. Evidence for apostatic selection by wild passerines. Nature, 220, 501-502.

BANTOCK, C. R. AND HARVEY, P. H. 1974. Colour polymorphism and selective predation experiments. J. Biol. Educ., 8, 323-329.

BOND, A. B. 1983. Visual search and selection of natural stimuli in the pigeon: the attention threshold hypothesis. J. Expt. Psychol., 9, 292-386.

BRYAN, J, E. 1973. Feeding history, parental stock, and food selection in rainbow trout. Behaviour, 45, 123-153.

CLARKE, B. C. 1962. Balanced polymorphism and the diversity of sympatric species. In D. Nichols (ed.), Taxonomy and Geography, Systematics association, Oxford, pp. 47-70.

COOK, L. M. 1971. Coefficients of natural selection. Hutchinson, London.

COOK, L. M. AND MILLER, P. 1977. Density dependent selection on polymorphic prey-some data. Amer. Nat., 111, 594-598.

COOPER, J. M. 1984. Apostatic selection on prey that match the background. Biol. J. Linn. Soc, 23 (in press).

CROZE, H. T. 1970. Searching image in carrion crows. Beihefte Z. Tierpsychol., 5, 1-85.

CURIO. E. 1976. The ethology of predation. Springer-Verlag, Berlin.

DAWKINS, M. 1971. Shifts of "attention" in chicks during feeding. Anim. Behav., 19, 575-582.

GREENWOOD, J. J. D., WOOD, E. M. AND BATCHELOR, S. 1981. Apostatic selection of distasteful prey. Heredity, 57, 27-34.

HARVEY, P. H., BIRLEY, N. AND BLACKSTOCK, T. H. 1975. The effect of experience on the selective behaviour of song thrushes feeding on artificial populations of Cepaea. Genetica, 45, 211-216.

HORSLEY, D. T. 1978. The role of avian predators in maintaining colour polymorphism. Ph.D. thesis, University of Nottingham.

HORSLEY, D. T., LYNCH, B. M., GREENWOOD, J. J. D., HARDMAN, B. AND MOSELY, S. 1979. Frequency-dependent selection by birds when the density of prey is high. J. Anim. Ecol., 48, 483-490.

LAWRENCE, E. S. 1985. Evidence for search image in Blackbirds Turdus merula L.: short-term learning. Anim. Behav. (in press).

LAWRENCE, E. S. AND ALlEN, J. A. 1983. On the term "search image". Oikos, 40, 313-314.

MOMENT, G. B. 1962. Reflexive selection: a possible answer to an old puzzle. Science, 136, 262-263.

MURRAY, J. 1972. Genetic diversity and natural selection. Oliver and Boyd, Edinburgh.

RAND, A. S. 1967. Predator-prey interactions and the evolution of aspect diversity. Atas do Simposio sôbre a Biota Amazonica, 5, 73-83.

RAYMOND, D. L. 1984. Wild birds prefer the familiar of striped and unstriped artificial prey. Biol. J. Linn. Soc., 23 (in press).

SOKAL, R. R. AND ROHLF, F. J. 1981. Biometry, 2nd edition. Freeman, San Fransisco.

TINBERGEN, L. 1960. The natural control of insects in pine woods. 1. Factors influencing the intensity of predation by songbirds. Arch. Néerl. Zool., 13, 265-343.

WILliS, A. J., McEWAN, J. W. T., GREENWOOD, J. J. D. AND ELTON, R. A. 1980. Food selection by chicks: effects of colour, density, and frequency of food types. Anim. Behav., 28, 874-879.

WRIGHT, A. A. 1979. Colour-vision psychophysics: a comparison of pigeon and human. In Granda, A. M. and Maxwell, J. H. (eds.) Neural mechanisms of behaviour in the pigeon, Plenum, New York, pp. 89-127. 